\title{
Long-term agricultural experiments inform the development of climate-smart agricultural practices
}

\author{
Studying cropping systems over decades illuminates slow-changing but important effects on soil \\ carbon, soil biota, water holding capacity and more.
}

by Kristina Wolf, Israel Herrera, Thomas P. Tomich and Kate Scow

\section{Abstract \\ California's Mediterranean agro-ecosystems are a major source of U.S. fruits and vegetables, and vulnerable to future extremes of precipitation and temperature brought on by climate change, including increased drought and flooding, and more intense and longer heat waves. To develop resilience to these threats, strategies are necessary for climate-smart management of soil and water. Long-term, large-scale, replicated ecological experiments provide unique testbeds for studying such questions. At the UC Davis Russell Ranch Sustainable Agriculture Facility (RRSAF), the 100-year Century Experiment, initiated in 1992, is investigating the effects of multiple farming practices in a farm-scale replicated study of 10 row crop cropping systems. It includes different fertility management systems: organic, conventional and hybrid (conventional plus winter cover crop) systems; different crops: wheat, tomatoes, corn, alfalfa, cover crops and grasslands; and different irrigation systems: rainfed, flood irrigated and drip irrigated. We briefly describe and report on a selection of long-term experiments conducted at RRSAF investigating soil management and irrigation practices, which are an important focus for developing climate-smart strategies in Mediterranean systems. For example, long-term monitoring of soil carbon content revealed that most crop systems have experienced a small increase in soil carbon since 1993, and increases in organically managed plots were substantially higher. As RRSAF continues to build upon this rich dataset from one of a very few long-term row crop experiments in Mediterranean ecosystems, it provides a testbed for identifying climate-smart solutions for these agronomically important ecosystems.}

$\Lambda$ gricultural productivity in the United States has increased dramatically over the last few decades, but in the face of climate change current management practices might not sustain current levels of production (Gregory et al. 2005; Lobell et al. 2008). Some practices that achieve high crop yields and profit - for example, minimal use of crop rotations, high rates of fertilizer and pesticide inputs, minimal carbon inputs and soil disturbance - also result in degradation of ecosystem processes on which agricultural systems rely. Such degradation can reduce resilience, making these systems more vulnerable to high temperatures and uncertainty in water supply, resulting in lower productivity in times of extreme weather conditions, such as prolonged drought (Tilman et al. 2002).

Climate-smart agriculture means increasing resiliency to extreme and unpredictable weather patterns induced by climate change by following three principles: (1) developing agricultural cropping systems that are productively resilient in the face of climate change; (2) reducing greenhouse gas emissions attributable to agriculture to further reduce contributions to global warming; and (3) proactively and adaptively managing farms in a way to buffer farm productivity and profitability against the negative effects of climate change.

To make informed, evidence-based management decisions under new climate change regimes, data is

Online: https://doi.org/10.3733/ca.2017a0022 
needed from long-term agricultural experiments, few of which exist. As weather and climate patterns change, repeated measurements over decades can reveal what may be slow but incremental changes in crop yield and quality, as well as soil quality and biodiversity

(Rasmussen et al. 1998).

\section{Century Experiment at RRSAF}

A long-term agricultural experiment, known as the Century Experiment, is underway at the Russell Ranch Sustainable Agriculture Facility (RRSAF), a unit of the Agricultural Sustainability Institute at UC Davis. RRSAF is a 285 -acre research facility and working farm where, under realistic commercialscale conditions, controlled long-term experiments are testing a variety of crop systems and management practices related to fertility and nutrient management, irrigation and water use, energy use, greenhouse gases and soil health.

The Century Experiment was designed as a 100year replicated experiment. It was initiated in 1992, when environmental and soil conditions were monitored as a baseline prior to installation in 1993 of 10 cropping systems across 72 one-acre plots; since then, one additional cropping system and restored native grassland reference plots have been introduced (table 1, fig. 1).
Soil and plant samples are collected regularly and analyzed, and subsampled for archive and future analysis. Crop yield and quality are measured annually at harvest. Energy use, inputs and outputs are monitored for all equipment and groundwater pumping throughout the year.

The interior of each 1-acre plot in the Century Experiment is maintained consistently for collection of the long-term dataset. Microplots and strips within each plot are available for additional experimental investigations, which have included the impacts of different fertilizers or crop varieties, pest management practices, tillage practices and soil amendments.

RRSAF research is also conducted in additional plots that are not part of the Century Experiment to focus on questions that explore practices that may ultimately be adopted within the main experiment. This research includes targeted investigations of soil amendments, irrigation frequency and type, and new crop varieties, and it permits side-by-side comparisons of management history on the effectiveness of different practices. UC and UC Agriculture and Natural Resources researchers and the RRSAF team collaborate regularly with local growers, as well as with researchers from other institutions throughout the United States and around the world, so that the research addresses local issues and also has broader relevance for agriculture in Mediterranean climates worldwide.

TABLE 1. Cropping rotations in 100-year study at Russell Ranch Sustainable Agriculture Facility

\begin{tabular}{|c|c|c|c|c|c|c|}
\hline System & Crop rotation & Replications & $\begin{array}{l}\text { Winter cover } \\
\text { crop (WCC)?* }\end{array}$ & Irrigationt & Fertilizer source & $\begin{array}{l}\text { Pesticide } \\
\text { management }\end{array}$ \\
\hline Organic tomato-corn & Tomato-corn & Six & Yes & Irrigated & Compost and WCC & Organic methods \\
\hline Transitional tomato-corn $¥$ & Tomato-corn & Three & Yes & Irrigated & Compost and WCC & Organic methods \\
\hline Legume tomato-corn & Tomato-corn & Six & Yes & Irrigated & $\begin{array}{l}\text { Mineral fertilizer and } \\
\text { WCC }\end{array}$ & Conventional methods \\
\hline Conventional tomato-corn & Tomato-corn & Six & No & Irrigated & Fertilizer & Conventional methods \\
\hline $\begin{array}{l}\text { Conventional wheat- } \\
\text { tomato }\end{array}$ & Wheat-tomato & Six & No & $\begin{array}{l}\text { Supplemental§ } \\
\text { when wheat; } \\
\text { irrigated fully when } \\
\text { tomato }\end{array}$ & Fertilizer & Conventional methods \\
\hline Alfalfa-tomato-corn & $\begin{array}{l}\text { Alfalfa-alfalfa- } \\
\text { alfalfa-tomato- } \\
\text { corn-tomato }\end{array}$ & Six & No & Irrigated & Mineral fertilizer & Conventional methods \\
\hline Wheat-fallow & Wheat-fallow & Six & No & Supplemental§ & Fertilizer & Conventional methods \\
\hline Wheat-fallow & Wheat-fallow & Six & No & Rainfed & Fertilizer & Conventional methods \\
\hline Wheat-fallow & Wheat-fallow & Six & No & Supplemental§ & None & Conventional methods \\
\hline Wheat-fallow & Wheat-fallow & Six & No & Rainfed & None & Conventional methods \\
\hline Wheat-legume & Wheat-legume & Six & Yes & Rainfed & WCC & Conventional methods \\
\hline $\begin{array}{l}\text { Native grass (reference } \\
\text { system) }\end{array}$ & $\begin{array}{l}\text { Perennial native } \\
\text { grasses planted } \\
\text { in } 2012\end{array}$ & Three & No & Rainfed & None & None \\
\hline
\end{tabular}

* The WCC is a bell bean, lana vetch and oat seed mix.

† Irrigation prior to 2014 was applied by flood (wheat) or furrow (tomato, corn). In 2015, subsurface drip irrigation (SSDI) was installed in tomato-corn plots. Alfalfa is irrigated by check-flood, and irrigated wheat by furrow-flood if needed.

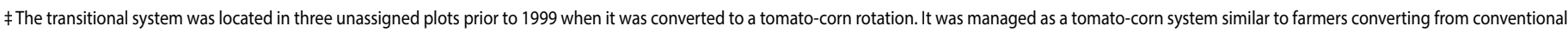
to organic, was managed with fully organic methods by 2000 , and certified organic by 2001. It has been managed like the organic tomato-corn system since.

$\S$ Wheat receives supplemental irrigation in plots that are not rainfed only when needed in excessively dry years, and at most two times in the winter, but in general receives no additional irrigation.

I All crop systems are 2-year rotations, except for alfalfa-tomato-corn, which is a 6-year rotation of 3 years alfalfa, followed by tomato-corn-tomato. 


\section{Soil chemistry, biology changes}

Maintaining healthy soils is a key to climate-smart agriculture. Properties such as porosity, water retention, drainage capacity, carbon sequestration, organic matter content and biodiversity all help to confer resilience to new pest and disease pressures and to extremes in temperature and water availability (Borron 2006; Dick 1992; Pretty 2008). The California Department of Food and Agriculture's Healthy Soils Initiative, launched in 2016, reflects the state's commitment to improve the quality of managed soils (CDFA 2016). Encouraging best practices for maintaining healthy soils will increase biodiversity as well as beneficial physical and chemical properties of soil. Improving these properties will, in turn, confer resilience of agro-ecosystems to uncertainties in climate, including unpredictable rainfall patterns, new extremes in temperature and unexpected shifts in the distribution of pests and diseases (Borron 2006; Pretty 2008).

Intensive soil sampling is a key part of the Century Experiment. Plots are sampled at least once every 10 years to as deep as 3 meters ( 9.8 feet) in eight depth intervals, and a number of chemical and physical properties are measured. After 20 years, cropping systems, with few exceptions (e.g., unfertilized wheat-fallow), either maintained or increased total soil carbon content to a depth of 2 meters ( 6.5 feet). Soil carbon increased significantly more in the organic tomato-corn system than it did in any other crops and management systems. Soil infiltration rates and aggregate stability were also greater in the organic than conventional tomatocorn system. This research also identified specific soil fractions where early changes in carbon sequestration can be detected, to help predict which practices promote increases or decreases in soil carbon.

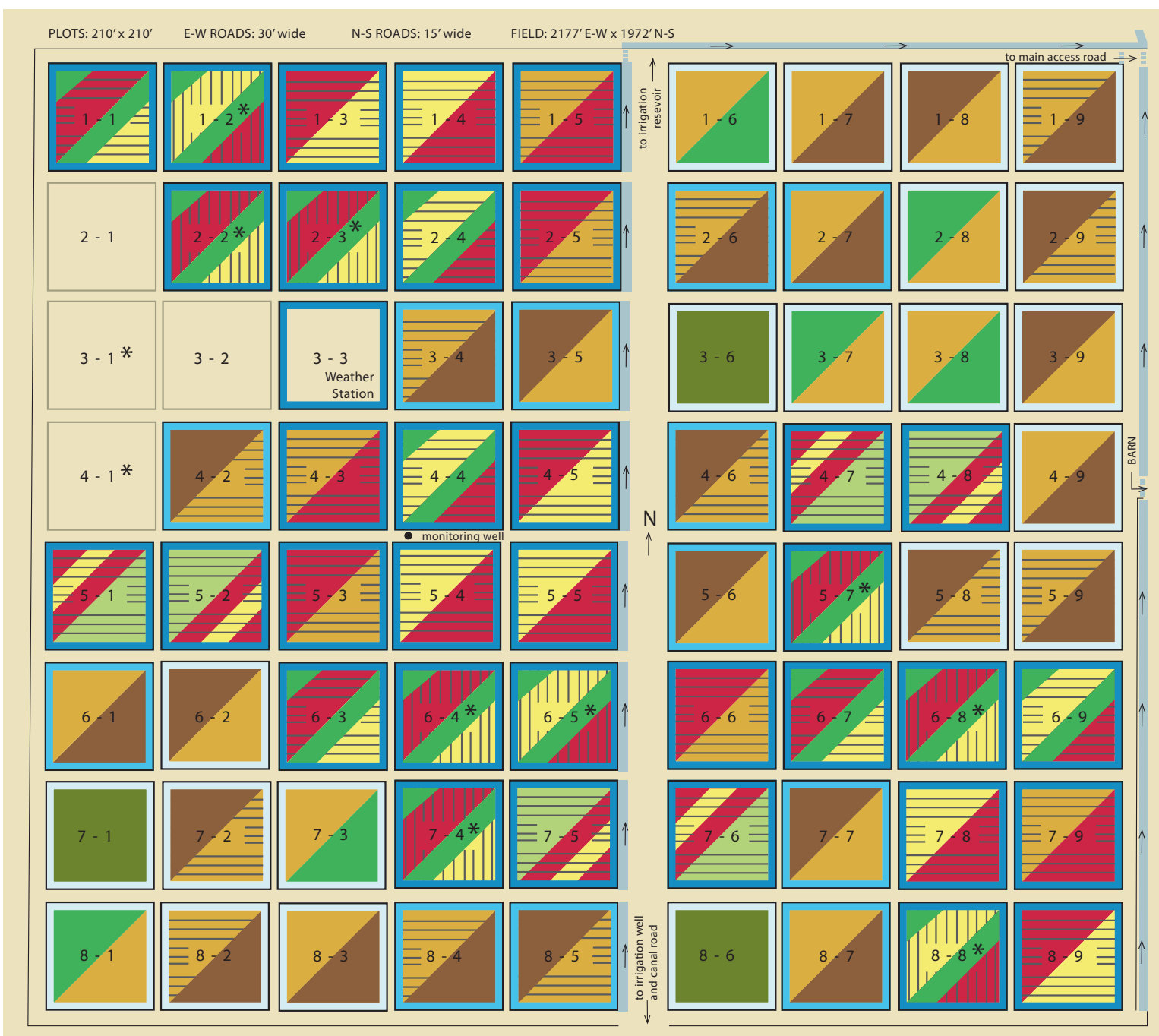

Russell Ranch Sustainable Agriculture Facility

Century Experiment

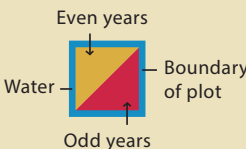

Crops:

Alfalfa

Corn

Native grass

Tomato

Wheat

Other

Fallow

Water:

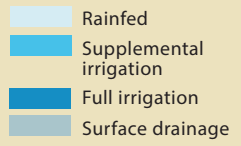

Nitrogen source:

Unfertilized

$\overline{\overline{\bar{N}}}$ Mineral fertilizer

|IIIIII Compost

Cover crop

* Certified Organic

Field location:

6 miles West of Rd 113 on

Russell Boulevard/Rd 32

\section{$0^{5} 0^{150}$}

Fig. 1. Experimental design of the Century Experiment at the Russell Ranch Sustainable Agriculture Facility, showing the 1-acre treatments in year 25 of the planned 100-year experiment. "Even and odd years" in the legend (upper right) refers to the sequence of crop harvest and does not apply to the 6-year alfalfa-corn-tomato rotation, which began in 2012. All crop systems are 2-year rotations, except for alfalfa-tomato-corn, which is a 6-year rotation: 3 years of alfalfa followed by tomato-corn-tomato. Cover crops are grown either as part of a two-year rotation with wheat (in the "wheatlegume" rotations) or as a winter crop in the tomato-corn rotation. Numbers within plots are identification numbers. See table 1 for further information. 
Changes in soil biology were evident as well: microbial biomass was $40 \%$ higher in soils in organic than in conventional tomato-corn rotations, and microbial community composition under organic and conventional management was distinctly different. More indepth analyses of the soil biota, including sequencing of soil microbial communities and measuring abundance of mycorrhizal fungi, are underway.

\section{Amendment, cover crop effects}

Use of agricultural and food wastes, and cover crops, can reduce dependency on synthetic fertilizers that rely on fossil fuels and generate greenhouse gases in their synthesis. Also, use of soil organic amendments helps organic and conventional growers to "close the loop" by reducing energy and environmental costs of waste disposal, and recycling valuable nutrients back into the soil. At RRSAF, composted poultry manure and winter cover crops provide sufficient nitrogen and other nutrients to the organic tomato-corn rotation. Organic tomato yields for 20 years under furrow irrigation were not significantly different from conventional tomato yields.

Soil amendments and winter cover crops have led to increased soil carbon sequestration, higher infiltration rates and greater aggregate stability in the organic system compared to the conventional systems; however, these benefits may be of limited interest to growers if yields are substantially reduced. A challenge is how to combine use of organic inputs with subsurface drip irrigation (SSDI) for organic systems. Organic relies on solid sources of fertility, for example, cover crops and compost, that cannot be delivered in the drip line, and that rely on microbial activity to convert them into plant-available forms. In SSDI systems, only a limited area of the bed is wetted and microbial activity may be reduced. Researchers at RRSAF are investigating the feasibility of using different combinations and forms of solid and liquid organic amendments in organic tomato-corn rotations. This is particularly timely as interest in organic farming and products increases (Jerkins and Ory 2016).

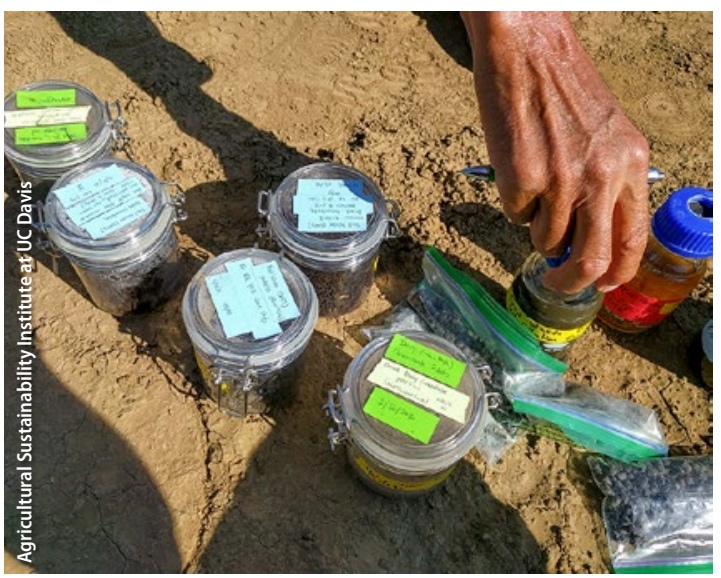

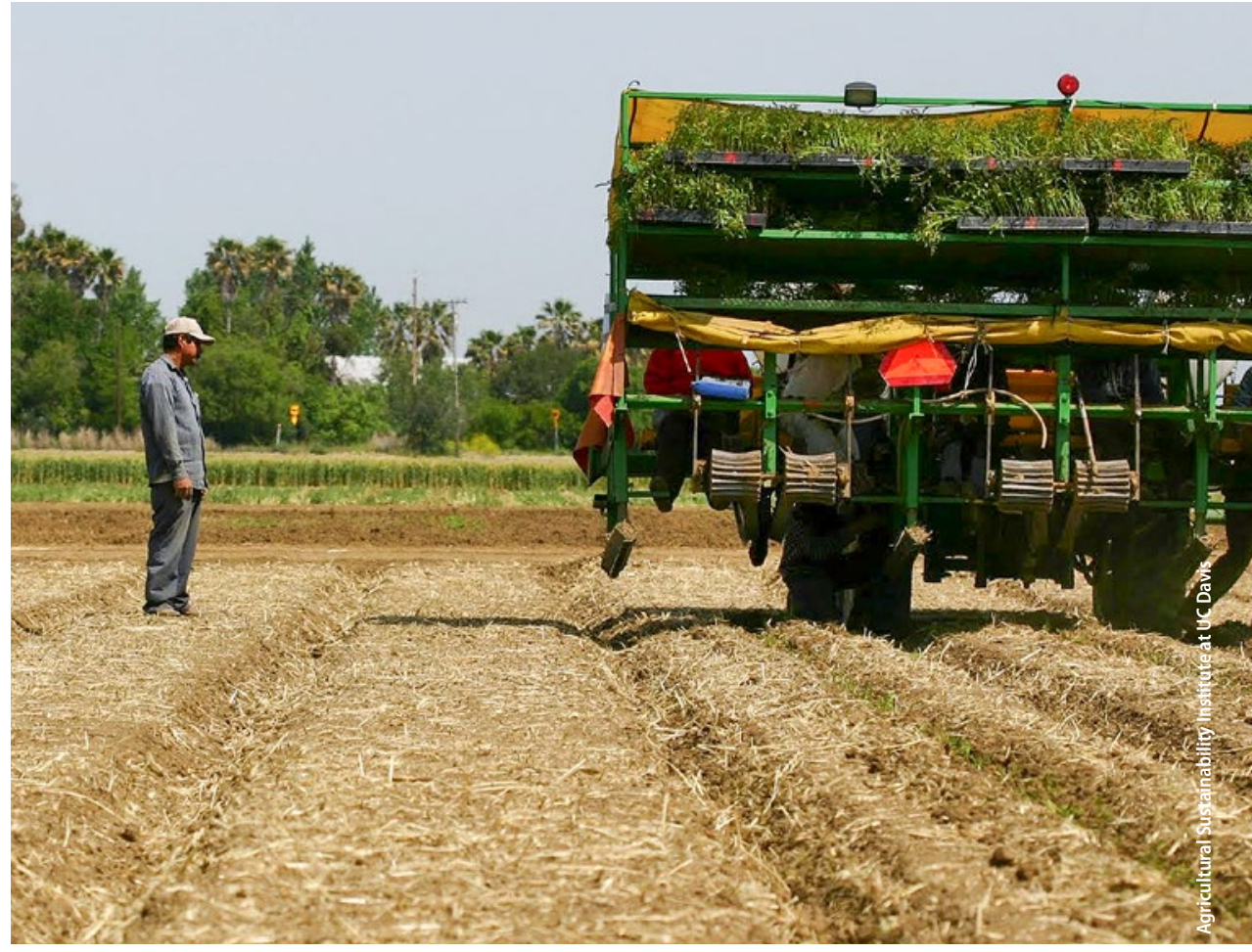

In 2012, a long-term experiment was initiated with the soil amendment biochar, a form of charcoal made from pyrolysis of organic waste materials. Application of biochar to tomato-corn rotations at 10 tons per hectare resulted in corn yields increasing in year 2 by approximately $8 \%$, but no other yield effects were observed over 4 years (Griffin et al. 2017). Biochar had no impact, however, on soil water retention. These results underscore the importance of being able to draw conclusions based on long-term research, and the experiment continues to be monitored.

\section{Water management}

Water quantity and quality are critical concerns for climate-smart agriculture in chronically drought-afflicted California (Dettinger et al. 2015; Mann and Gleick 2015). SSDI may increase crop yields, reduce weed pressure and improve water management in conventionally managed systems (Ayars et al. 2015), but the trade-offs associated with other impacts of SSDI, such as changes to soil moisture patterns, reduced microbial activity, altered accumulation of salts and reduced groundwater recharge, have received little attention. At RRSAF, researchers are comparing effects of furrow versus drip irrigation on crop yields, root growth, microbial communities and soil structure. Many changes, such as soil aggregate structure, are not evident immediately and require long-term experiments to understand and resolve.

Samples of biofertilizer in its various stages, from raw waste to fertilizer. Using cover crops and composted agricultural and food wastes lessens dependency on synthetic fertilizers, reduces waste disposal costs and recycles valuable nutrients back into the soil.
Planting tomatoes in soil with cover crop residue still present. The use of cover crops and soil amendments in Century Experiment plots has led to increased soil carbon sequestration, higher infiltration rates and in the organic systems compared to conventional systems. Such soil properties can help crop systems withstand the temperature extremes and pest and disease pressures that may occur as the climate changes. greater aggregate stability 
Researchers at RRSAF are evaluating new varieties of climate-smart crops, such as perennial wheat, for their yield and resilience in California's Mediterranean climate. Here, students hand harvest wheat for data collection.
Irrigation scheduling is another focus of water management at RRSAF. Different methods and associated technologies (some commercially available) have been compared for estimating irrigation needs, including methods based on evapotranspiration (ET), soil moisture sensors, plant water status and remote-sensing data. In tomatoes, an ET-based method was found to better predict crop water needs than soil sensor-based methods.

\section{Other research at RRSAF}

Research projects at RRSAF have also addressed other aspects of climate-smart agriculture. These include development of farm equipment that reduces soil

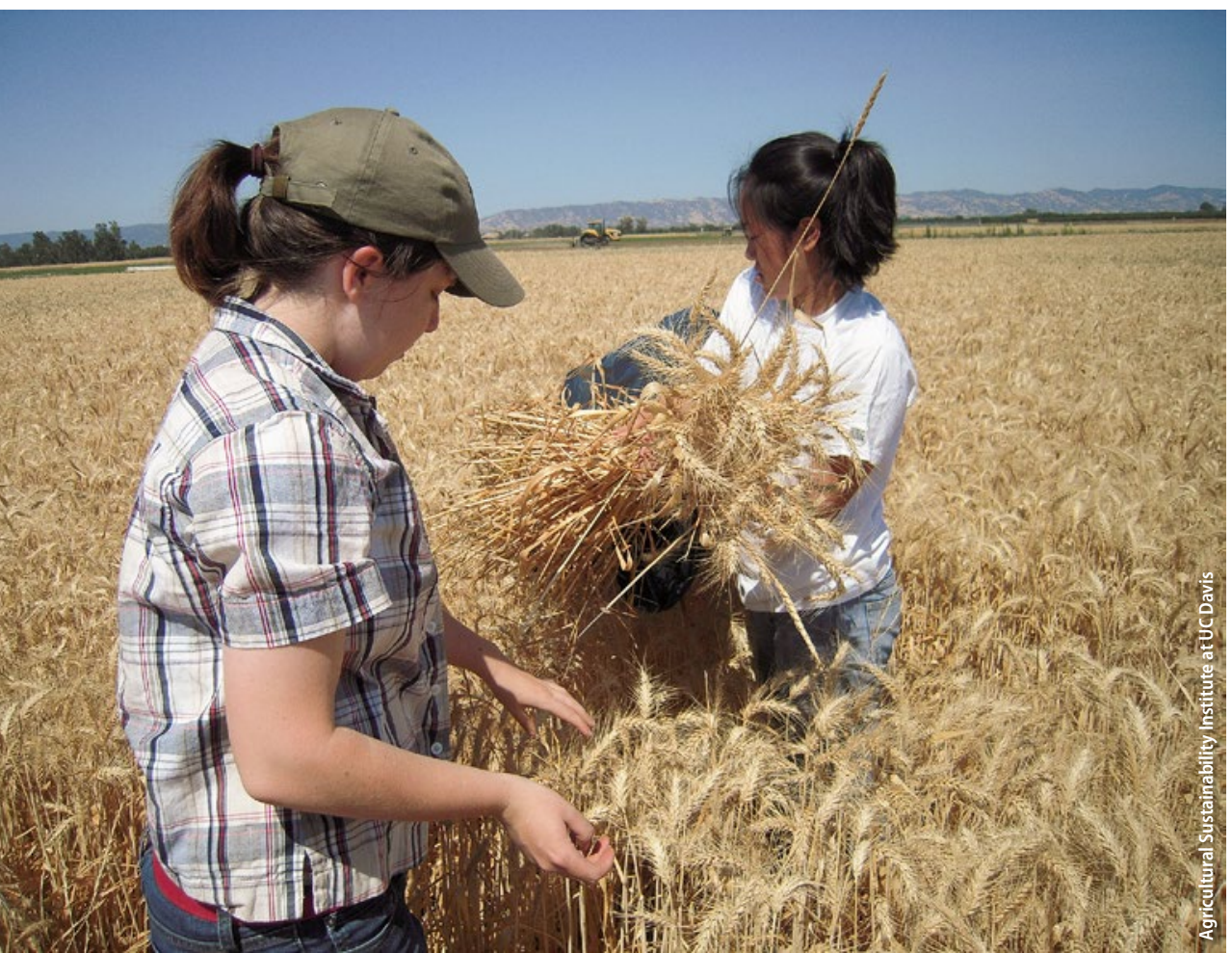

disturbance and energy consumption; application of sensor technology (soil and water sensors, airborne imaging spectrometers) in collaboration with NASA's Jet Propulsion Laboratory to support data-driven management choices in response to climate variation; and comparison of the efficacy of smart water meters in groundwater wells and irrigation systems.

Other investigations have measured the feasibility of using dairy and food waste biodigestate (product of anaerobic bioreactors) that can help offset consumption of fossil-fuel based fertilizers; tracking changes in wheat cellulose via isotopic methods to monitor plant responses to climate change; and measuring lower greenhouse gas emissions under SSDI than furrow irrigation. New varieties of climate-smart crops, such as perennial wheat, are being evaluated for their yield and resilience in California's Mediterranean climate.

In its 20 years, the Century Experiment has demonstrated a unique value in generating climate-smart data - for example, which practices enhance carbon sequestration in California row crop soils, how irrigation can be managed to reduce greenhouse gas emissions, and what sensors help most in reducing water consumption. Future research will address how soil biodiversity, such as the symbiotic mycorrhizal fungi, can be harnessed to reduce water and nutrient inputs, and increase crop resilience. Researchers exploring mechanisms driving short- and long-term responses to global change can guide the development of decision support models that incorporate economic, agronomic, ecological and social trade-offs and provide support for decision-makers - growers, policymakers, researchers - to make management decisions in the face of increasing climate uncertainty. CA

K. Wolf is Senior Ecologist at H.T. Harvey \& Associates; I. Herrera is Principal Superintendent of Agriculture at Russell Ranch; T.P. Tomich is Director of the Agricultural Sustainability Institute; and K. Scow is Professor of Soil Science and Microbial Ecology in the Dept. of Land, Air and Water Resources at UC Davis and Director of Russell Ranch.

\section{References}

Ayars JE, Fulton A, Taylor B. 2015 Subsurface drip irrigation in California-Here to stay? Agr Water Manage 157:39-47. Borron S. 2006. Building Resilience for an Unpredictable Future: How Organic Agriculture Can Help Farmers Adapt to Climate Change. Food and Agriculture Organization of the United Nations, Rome. 25 p.

[CDFA] California Department of Food and Agriculture. 2016 Healthy Soils Action Plan. CDFA, Sacramento, CA. www.cdfa. ca.gov/oefi/healthysoils/docs/ CA-HealthySoilsActionPlan.pdf (accessed Nov. 21, 2016).
Dettinger M, Udall B, Georgakakos A. 2015. Western water and climate change. Ecol Appl 25:2069-93

Dick RP. 1992. A review: Longterm effects of agricultural systems on soil biochemical and microbial parameters. Agr Ecosyst Environ 40:25-36.

Gregory PJ, Ingram JS, Brklacich M. 2005. Climate change and food security. Philos T Roy Soc B 360:2139-48.
Griffin DE, Wang D, Parikh SJ, Scow KM. 2017. Short-lived effects of walnut shell biochar on soils and crop yields in a long-term field experiment. Agr Ecosyst Environ 236:21-9.

Jerkins D, Ory J. 2016. 2016 National Organic Research Agenda: Outcomes and Recommendations from the 2015 National Organic Farmer Survey and Listening Sessions. Organic Farm ing Research Foundation, Santa Cruz, CA. 128 p.
Kong AY, Six J, Bryant DC, et al. 2005. The relationship between carbon input, aggregation, and soil organic carbon stabilization in sustainable cropping systems. Soil Sci Soc Am J 69:1078-85.

Lobell DB, Burke MB, Tebaldi C, et al. 2008. Prioritizing climate change adaptation needs for food security in 2030. Science 319:607-10.

Mann ME, Gleick PH. 2015 Climate change and California drought in the 21st century. $P$ Natl Acad Sci USA 112:3858-9.
Pretty J. 2008. Agricultural sustainability: Concepts, principles and evidence. Philos T Roy Soc B 363:447-65.

Rasmussen PE, Goulding KWT, Brown JR, et al. 1998. Long-term agroecosystem experiments: Assessing agricultural sustainability and global change. Science 282:893-6.

Tilman D, Cassman KG, Matson PA, et al. 2002. Agricultural sustainability and intensive production practices. Nature 418:671-7. 